\title{
Vertical Mergers, Raising Rivals' Costs and Foreclosure in a Network Industry
}

\author{
Adekola Oyenuga \\ Adekola Oyenuga Energy Consulting, Nyjordstubben 156, 1275, Oslo, Norway \\ Email: adekola_oyenuga@yahoo.no
}

Received 22 September 2013; revised 29 November 2013; accepted 29 December 2013

Copyright (C) 2014 by author and Scientific Research Publishing Inc.

This work is licensed under the Creative Commons Attribution International License (CC BY). http://creativecommons.org/licenses/by/4.0/

(c) (i) Open Access

\begin{abstract}
Foreclosure through raising a network rival's costs may not be detrimental in the short-term, but in the longer-term it may allow a predator to expand its market share. The focus of antitrust opinion in assessing potential vertical mergers should therefore be on the longer-term effects of such mergers.
\end{abstract}

Keywords

Vertical Structure, Oligopoly, Antitrust Policy, Congestion Externalities, Network Effects

\section{Introduction}

The controversy amongst economic scholars and antitrust authorities on the competitive effects of vertical mergers remains unresolved. On one side of the debate are advocates of the so called Chicago school, who view vertical mergers as having mainly pro-competitive effects. In their viewpoint, vertical mergers serve to eliminate double markups and resolve co-ordination problems, thereby boosting efficiency in a supply chain (see [1]-[4]).

Opposing this viewpoint, however, are arguments that have been characterized as belonging to the Post-Chicago school. Post-Chicago adherents maintain that vertical mergers serve a strategic purpose by resolving commitment problems in the supply chain, and could therefore have substantial anti-competitive effects given that the likelihood of vertical foreclosure becomes increased (see [5] [6]). ${ }^{1}$

The economic literature provides useful definitions of what vertical foreclosure is. For example, [5], p. 127, defines it as: “... the exclusion that results when unintegrated downstream rivals are foreclosed from the input supplies controlled by the firm that integrates” [7], p. 1, views foreclosure as: “... a dominant firm's denial of proper access to an essential good it produces, with the intent of extending monopoly power from one segment

${ }^{1}$ See [7] [9]-[11] for recent reviews of the economic and antitrust literature on the competitive effects of vertical mergers and foreclosure. 
of the market (the bottleneck segment) to an adjacent segment (the potentially competitive segment)”.

It is important to note that while not all vertical mergers will necessarily result in foreclosure, the strategic rationality of competing firms suggests that vertical mergers and foreclosure should be expected to occur whenever such outcomes are profitable, and can be implemented with minimal risk of the predator being discovered and having to face costly anti-trust sanctions. A clear inference is that a sound position on the competitive effect of vertical mergers may at best be characterized on a case-by-case or industry-specific basis.

The recently released European Union's (EU) non-horizontal merger guidelines, $[8]^{3}$, are meant to help resolve this controversy by providing guidance as to how the Commission assesses mergers where the entities involved are active at different stages of a supply chain. ${ }^{4}$ The guidelines define foreclosure as: “... any instance where actual or potential rivals' access to supplies or markets is hampered or eliminated as a result of the merger, thereby reducing these companies' ability and/or incentive to compete”.

Paragraph 13 provides the following comment on the pro-competitive effects of vertical mergers:

A characteristic of vertical mergers and certain conglomerate mergers is that the activities and/or the products of the companies involved are complementary to each other. The integration of complementary activities or products within a single firm may produce significant efficiencies and be pro-competitive.

Paragraphs 15 and 18 address the anti-competitive effects of vertical mergers:

However, there are circumstances in which non-horizontal mergers may significantly impede effective competition, in particular as a result of the creation or strengthening of a dominant position...Non-coordinated effects may principally arise when non-horizontal mergers give rise to foreclosure. As a result of such foreclosure, the merging companies — and, possibly, some of its competitors as well—may be able to profitably increase the price charged to consumers. These instances give rise to a significant impediment to effective competition and are referred to hereafter as "anticompetitive foreclosure".

Critically, paragraph 32 reveals the basis adopted by the Commission for identifying the likelihood of anticompetitive foreclosure consequent upon a vertical merger:

In assessing the likelihood of an anti-competitive input foreclosure scenario, the Commission examines, first, whether the merged entity would have, post-merger, the ability to substantially foreclose access to inputs, second, whether it would have the incentive to do so, and third, whether a foreclosure strategy would have a significant detrimental effect on competition downstream. ${ }^{5}$

The objective of this paper is to examine the implications of paragraph 32 in assessing the likelihood of anticompetitive input foreclosure in a network industry. This means that we will examine conditions under which an entity at the downstream/retail stage of a network industry's supply chain will, post-vertical merger, have the incentive and the ability to raise the input costs of an independent rival at the retail stage, and whether such a foreclosure strategy will have a detrimental effect on retail competition.

To give a clearer understanding of these terms, paragraph 34 specifies that the "ability to foreclose" may raise competition problems only if it concerns an important input for the downstream product. Paragraph 40 describes the "incentive to foreclose" as depending on the degree to which the strategy will be profitable, and paragraph 47 specifies that a merger will raise competition concerns because of input foreclosure when it would lead to increased prices in the downstream market, thereby significantly impeding effective competition.

A distinguishing feature of network industries is the presence of a common access infrastructure network for conveying inputs/service from an upstream market to final consumers on a downstream retail market. ${ }^{6}$

Homogeneity of the input implies that inputs belonging to competing retail firms are indistinguishable while being transported through the network. Consequently, negative/cost-related externalities may arise between rival firms owing to their joint usage of the network. This is because an increase in the input purchased by an individual retail firm "imposes" an increase in the network cost on all other retailers. Myopically however, the

\footnotetext{
${ }^{2}$ According to [7], foreclosure can arise when an essential facility or bottleneck good (for example, a scarce commodity or infrastructure network) is used as an input by a potentially competitive downstream industry, or when it is sold directly to customers, who use the good in conjunction with other, perhaps complementary goods (for example, system goods or after sales services).

${ }^{3}$ See [8] on the assessment of non-horizontal mergers under the Council Regulation on the control of concentrations between undertakings.

${ }^{4}$ Op. cit. paragraph 2 .

${ }^{5} \mathrm{~A}$ similar procedure is suggested by [12], p. 690, which involves ascertaining that: (1) The alleged predator actually performed the alleged deed; (2) The action allowed the achievement of market power; (3) The conduct injured competitors; and (4) Consumers suffered harm as a consequence.

${ }^{6}$ The infrastructure network is a defining feature of so-called network industries such as telecommunications, postal service, airlines, electricity, natural gas, water and railroads.
} 
responsible firm may not fully consider the impact that its action will have on others, hence the negative externality. ${ }^{7}$

As we however identify in this paper, this negative externality may be used to raise network costs, and to strategically foreclose rivals. This provides a new perspective for assessing the anti-competitive effects of vertical mergers, since they would normally result in an expansion of input utilization due to the elimination of double marginalization. It is therefore important to understand when vertical mergers in network industries could be used in anti-competitive foreclosure through raising network costs. ${ }^{8}$

Raising rivals' costs has been identified as an attractive foreclosure strategy. ${ }^{9}$ This means that the likelihood of its being implemented following a vertical merger, or serving to motivate mergers that would otherwise notarise should not be ignored (see [13]-[17]).

According to [18] raising rivals' costs may be profitable without even requiring that a rival exit the market. And unlike other foreclosure strategies that focus on lowering rivals' revenues, it does not require trading-off shorter-term losses against higher and uncertain longer-term profits. Also, strategically raising rivals' costs may be (by far) less costly to implement than lowering rivals' revenues.

To buttress these points, [12] argues that by successfully raising its rivals' costs, a firm can secure the market power needed to maintain a supra-competitive price on an otherwise keenly contested final market. ${ }^{10}$ Raising rivals' costs can be accomplished through the use of an overbuying strategy, whereby the cost of an input is pushed-up as a predating firm strategically increases its purchase of the input (see [12] [18]).

This suggests a rising (and possibly convex) input cost function that could be the result of scarcity or decreasing returns in production of the input. An increasing input cost function could also be reflective of the usage cost for an infrastructure network, particularly when the network's capacity is congested. As payment for using the network, a transport cost component is added to the cost of each unit of input on the retail market.

While unique approaches to defining the transport cost may be adopted to suit the technical conditions of particular industries (for example the use of nodal pricing in electricity networks), it is not unusual to specify the transport cost as a uniform charge (per unit of input) that is a function of total network usage.

For example, [16] examines how an increase in the cost of a variable factor of production would affect rents in a competitive industry with an elastic factor supply and inelastic demand. It models the factor's cost to be an increasing function of the total factor demand. [20] examines the effect of introducing competition in a hub-and-spoke airline network and identify the marginal cost of transporting a passenger through the network to be decreasing in the traffic density (that is: the total number of passengers using a given network). Similarly, [21] identifies infrastructure network costs for United States (US) railroads to be a positive function of the level of network maintenance (measured by the total number of replaced railway ties), which is increasing in the total usage of the network. ${ }^{11}$

Yet another example is [22] that investigates alternative organizational options for the upstream infrastructure and downstream operations segments in the European Union (EU) railway industry. Restricting their analysis to just two countries, they model the cost of the infrastructure network in each country as a function of the country's total network usage.

In the electricity industry, the cost of retail power supply is plausibly increasing in the total volume transported across the grid network. The justification for this assertion is threefold and because the cost of retail power supply can be broken down into three basic components viz.: the wholesale energy cost, the cost of transmission losses and the cost of network maintenance (see [23]).

First, the wholesale energy cost is increasing in the total volume of power generated and transported across the power system due to the rising marginal cost profile of power plants that must be dispatched to meet an

\footnotetext{
${ }^{7}$ In the case of the electricity industry, the use of nodal pricing can internalize this externality by defining a network cost for each unit of input that "reflects" the additional cost imposed on other network users.

${ }^{8}$ [19] also examines a case in which the transmission network is strategically used by competing retail suppliers.

${ }^{9}$ Also termed input foreclosure, raising rivals' costs is an example of so-called non-price or cost-based foreclosure strategies. [18] lists other examples of non-price foreclosure strategies as: exclusive dealing arrangements; inducing input suppliers to discriminate against rivals; lobbying regulators or regulatory agencies to create regulations that disadvantage rivals; commencing R\&D and advertising wars; and adopting incompatible technologies.

${ }^{10}$ This is because a rival with relatively high input costs will have reduced incentives to act aggressively, either by reducing its price or raising its output, on the final market.

${ }^{11}$ This is because in the US railroad industry, most infrastructure-related activity (and costs) arise from maintaining existing networks rather than expanding them. In 1996 for example, US railroads installed 14.3 million ties and 840,000 tons of rail of which $94.25 \%$ and $95.6 \%$ respectively were for replacement rather than addition purposes.
} 
increasing retail demand. Second, transmission losses are conventionally modelled as a quadratic function of the total volume transported across the network, implying that the cost of such losses is increasing in the total volume transported. Third, the network maintenance or grid cost is a positive function of the total volume transported across the network and the number of power plants connected to the system. ${ }^{12}$

The propensity of a cost-raising vertical merger to result in anti-competitive foreclosure lies in its ability to impact retail costs (which is to say the sum of the input and network costs) for otherwise symmetric retailrivals, asymmetrically. Such a vertical merger would mean that the input costs of the merged entity face downward pressure due to the elimination of double marginalization, while the input costs for the independent rivalmay rise with the monopolization of the input market. Strategically speaking, raising network costs would be profitable when the profit margin from the merged retail supplier's expansion on the retail market exceeds the total costs it incurs in making the expansion.

While foreclosure through raising rival's costs in networks may not be detrimental to consumers in the short-term, it however provides the wherewithal for a seemingly benign expansion in the predator's market share that may, over the longer-term, provide the basis for the more harmful use market power. The emphasis for antitrust opinion in potential vertical mergers of this nature should therefore be on the longer-term implications to the strategic acquisition/increase of retail market share.

Other examples where oligopolists have utilized the network strategically are [19] who examine the strategic congestion of an electricity network by rival oligopolists, and [13] who examine Standard Oil's monopolization of the United States' petroleum refining sector in the late nineteenth century, through raising rival's costs for shipments through the railroad network.

The paper is organized as follows: The model is presented in the next section. Section 3 examines the benchmark case of a vertically separated network industry. Section 4 examines the incentive of a retail supplier to strategically raise network costs. Section 5 examines the post-merger network industry for the ability of the merged entity to foreclose the rival. Section 6 examines whether the merger has had a detrimental effect on retail prices with linear demand. Section 7 discusses the policy implications of the results, and Section 8 concludes.

\section{The Model}

Assume a simple successive duopoly model in a network industry. The vertical structure comprises of an upstream market for a homogenous input, a downstream retail market and an infrastructure network connecting the upstream and downstream stages. There is no storage. We assume that firms are symmetric and independent at both stages. Downstream retail suppliers and upstream input producers are denoted by the subscripts: $i, j=1,2$ respectively. ${ }^{13}$

Producer $j$ 's payoff is:

$$
\pi_{j}^{w}=\left[p^{w}(Q)-c\left(q_{j}\right)\right] q_{j}
$$

where $q_{j}$ is output for $j=1,2 ; Q=q_{1}+q_{2}$ is the total upstream output; and $p w(Q)$ is the input market's concave inverse demand function evaluated at $Q$. The upstream average production cost is $c\left(q_{j}\right)$ while the total and marginal production costs are denoted as:

$$
C\left(q_{j}\right)=c\left(q_{j}\right) q_{j} \text { and } C\left(q_{j}\right)=c\left(q_{j}\right)+c^{\prime}\left(q_{j}\right) q_{j}>0
$$

respectively.

The transport cost per-unit of input is:

$$
M(X)>0
$$

where $X$ is the total input demand. The transport cost is assumed to be strictly positive and increasing inthe total input demand. This means we will also have:

\footnotetext{
${ }^{12}$ Although the network maintenance cost could in specific instances—subject to the geographical dispersal of transferring units and the direction of network flows-be ambiguously related to the total transported volume, it is not unusual to assume that this cost would be generally increasing in the total transported volume.

${ }^{13}$ The duopoly restriction is imposed for simplicity and may be easily relaxed to reflect an oligopolistic situation. Furthermore, all interactions are assumed to occur in a static setting with full information and no uncertainty.
} 


$$
M^{\prime}(X)>0
$$

Retail supplier's payoff is:

$$
\pi_{i}^{r}=\left[p^{r}(X)-M(X)-p^{w}\right] x_{i}
$$

where $x_{i}$ is the retail market quantity for $i=1,2 ; X=x_{1}+x_{2}$ is the total retail demand which is equal tothe total input demand and $p^{r}(X)$ is the retail market's concave inverse demand function evaluated at $X$. The cost of the input $p^{w}$ is exogenous on the retail market.

It is assumed that retail suppliers do not make significant modifications to the input at the downstream stage, meaning that the total upstream output is always equal to the total retail demand, or that:

$$
Q=X
$$

The equilibrium concept on the input and retail markets is Cournot-Nash. Which means that quantity is the strategic variable at both stages and that each player's choice of quantity is required to be a best-response to the rival's choice. Modelling Cournot competition at the upstream and downstream stages corresponds toa realworld situation in which retail suppliers are first assumed to compete for market shares on the retail market, after which they place orders on the upstream input market to purchase equivalent amounts of the input.

On the upstream market, producers compete to determine what share of the total input demand each will satisfy. [24] [25] argue that the outcome of a one-stage Cournot game would be equivalent to that of a two-stage game (as we present here) in which the players first make investment or capacity choice decisions, before proceeding to compete on price. The necessary assumptions for this to be true are that demand be concave, rationing efficient and investment costs arbitrary.

This means that the two-stage/vertical Cournot model that we develop in this paper would, subject to the necessary assumptions being fulfilled, also be appropriate for analyzing a vertically structured network industry in which retail suppliers first commit themselves on an upstream market to given levels of input purchases, for example, through forward purchases, which could be interpreted as a type of capacity choice, and thereafter proceed to compete on the retail market using price as the strategic variable.

\section{Vertical Separation-The Benchmark}

We start by deriving the equilibrium outcomes for the industry pre-vertical merger. Applying the backward induction approach, the analysis will start on the retail market before proceeding to the input market.

\subsection{The Retail Market}

Retail supplier $i=1,2$ solves the problem in (Equation (2)) with respect to $x_{i}>0$ to obtain the first-order condition:

$$
\operatorname{FOC}\left(x_{i}\right)=\frac{\mathrm{d} \pi_{i}^{r}}{\mathrm{~d} x_{i}}=\left[\frac{\mathrm{d} p^{r}}{\mathrm{~d} x_{i}}-\frac{\mathrm{d} M}{\mathrm{~d} x_{i}}\right] x_{i}+\left[p^{r}-M-p^{w}\right]=0
$$

where $\frac{\mathrm{d} p^{r}}{\mathrm{~d} x_{i}} x_{i}+p^{r}$ is the marginal revenue $i$ earns from delivering an additional unit of the product to the retail consumers, and $\frac{\mathrm{d} M}{\mathrm{~d} x_{i}} x_{i}+M+p^{w}$ is the marginal cost of an additional unit of input purchased on the inputmarket. Observe that we have used $\mathrm{d} X / \mathrm{d} x_{i}=1$. The FOC simply equates I's marginal revenue with the marginal cost of the input on the retail market.

The second-order condition is:

$$
\operatorname{SOC}\left(x_{i}\right)=\frac{\mathrm{d}^{2} \pi_{i}^{r}}{\mathrm{~d} x_{i}^{2}}=\left[\frac{\mathrm{d}^{2} p^{r}}{\mathrm{~d} x_{i}^{2}}-\frac{\mathrm{d}^{2} M}{\mathrm{~d} x_{i}^{2}}\right] x_{i}+2\left[\frac{\mathrm{d} p^{r}}{\mathrm{~d} x_{i}}-\frac{\mathrm{d} M}{\mathrm{~d} x_{i}}\right]<0
$$

which is satisfied with: $\mathrm{d} p^{r} / \mathrm{d} x_{i}<0 ; \mathrm{d}^{2} p^{r} / \mathrm{d} x_{i}^{2} \leq 0$ and $\mathrm{d} M / \mathrm{d} x_{i}>0 ; \mathrm{d}^{2} M / \mathrm{d} x_{i}^{2} \geq 0$ implying a concave 
retail demand and convex network transport costs. Differentiating $i=1$ 's first-order condition with respect to the rival's quantity gives the cross-partial derivative as:

$$
\frac{\mathrm{d}^{2} \pi_{i}^{r}}{\mathrm{~d} x_{1} \mathrm{~d} x_{2}}=\left[\frac{\mathrm{d}^{2} p^{r}}{\mathrm{~d} x_{1} \mathrm{~d} x_{2}}-\frac{\mathrm{d}^{2} M}{\mathrm{~d} x_{1} \mathrm{~d} x_{2}}\right] x_{1}+\left[\frac{\mathrm{d} p^{r}}{\mathrm{~d} x_{2}}-\frac{\mathrm{d} M}{\mathrm{~d} x_{2}}\right]<0
$$

which says that the retail quantities are strategic substitutes and is satisfied with $\mathrm{d}^{2} p^{r} / \mathrm{d} x_{1} \mathrm{~d} x_{2} \leq 0$ and $\mathrm{d}^{2} M / \mathrm{d} x_{1} \mathrm{~d} x_{2} \geq 0$. From the foregoing, we can identify that retail supplier $i=1$ 's optimal retail quantity will be a function of the rival's quantity and the upstream cost of the input:

$$
x_{1}^{*}=x_{1}^{*}\left(x_{2}, p^{w}\right)
$$

A symmetric expression is valid for the rival $i=2$.

\section{Comparative Statics}

Simple comparative statics show that:

$$
\left.\frac{\mathrm{d} x_{i}^{*}}{\mathrm{~d} p^{w}}\right|_{\mathrm{d} \pi_{i}^{r}=0}=\frac{1}{\operatorname{SOC}\left(x_{i}\right)}<0
$$

which says that the optimal retail quantity is decreasing in the price of the input at a rate equal to the inverse of the second-order condition. Similarly, we will have that:

$$
\left.\frac{\mathrm{d} x_{i}^{*}}{\mathrm{~d} x_{2}}\right|_{\mathrm{d} \pi_{i}^{r}=0}=-\frac{\mathrm{d}^{2} \pi_{i}^{r}}{\mathrm{~d} x_{1} \mathrm{~d} x_{2}} \frac{1}{\operatorname{SOC}\left(x_{i}\right)}<0
$$

which implies that a reduction in the rival's retail quantity must be compensated by an increase in the retail supplier's own quantity and vice-versa. This is consistent with the assumption that the optimal quantities are strategic substitutes.

\subsection{The Input Market}

On the input market producer $j=1$ maximises the Lagrange problem:

$$
L_{1}\left(q_{1}, \lambda\right)=\left[p^{w}(Q)-c\left(q_{1}\right)\right] q_{1}+\lambda\left[X-q_{1}-q_{2}\right]
$$

The Lagrange formulation in (Equation (9)) says that each producer is not merely interested in maximising its profit from production and sale on the input market, but also recognises that the supply-demand balance constraint must be satisfied. ${ }^{14}$ Holding the rival's output fixed, this implies that a change in the total input demand would require that the producer adjust its own output to keep the constraint satisfied. $\lambda$ is the shadow price on the supply-demand balance constraint.

Choosing the upstream output $q_{1}>0$ gives the first-order conditions:

$$
\operatorname{FOC}\left(q_{1}\right)=\frac{\mathrm{d} L_{1}}{\mathrm{~d} q_{1}}=\left[\frac{\mathrm{d} p^{w}}{\mathrm{~d} q_{1}}-\frac{\mathrm{d} c}{\mathrm{~d} q_{1}}\right] q_{1}+\left[p^{w}-c\right]-\lambda=0
$$

which is also:

$$
\frac{\mathrm{d} \pi_{1}^{w}}{\mathrm{~d} q_{1}}=\lambda
$$

And

$$
\operatorname{FOC}(\lambda)=\frac{\mathrm{d} L_{1}}{\mathrm{~d} \lambda}=X-q_{1}-q_{2}=0 ; \quad \lambda \geq 0
$$

\footnotetext{
${ }^{14}$ Satisfying the supply-demand equalisation constraint is an essential condition in some networks such as electricity.
} 
Given that: $\frac{\mathrm{d} p^{w}}{\mathrm{~d} q_{1}} q_{1}+p^{w}$ is the marginal revenue and: $\frac{\mathrm{d} c}{\mathrm{~d} q_{1}} q_{1}+c$ is the marginal cost for producer $j=1$ on the input market, the FOCs in Equation (10) and Equation (11) show that a producer equates the marginal profit on the input market with the shadow price on the supply-demand balance constraint. The FOC in Equation (12) says that the total input demand must be equalised with the total upstream output.

The second-order condition is:

$$
\operatorname{SOC}\left(q_{1}\right)=\frac{\mathrm{d}^{2} L_{1}}{\mathrm{~d} q_{1}^{2}}=\left[\frac{\mathrm{d}^{2} p^{w}}{\mathrm{~d} q_{1}^{2}}-\frac{\mathrm{d}^{2} c}{\mathrm{~d} q_{1}^{2}}\right] q_{1}+2\left[\frac{\mathrm{d} p^{w}}{\mathrm{~d} q_{1}}-\frac{\mathrm{d} c}{\mathrm{~d} q_{1}}\right]-\frac{\mathrm{d} \lambda}{d q_{1}}<0
$$

which is also:

$$
\frac{\mathrm{d}^{2} \pi_{1}^{w}}{\mathrm{~d} q_{1}^{2}}<\frac{\mathrm{d} \lambda}{\mathrm{d} q_{1}}
$$

and is satisfied with $\frac{\mathrm{d} p^{w}}{\mathrm{~d} q_{1}}<0 ; \frac{\mathrm{d}^{2} p^{w}}{\mathrm{~d} q_{1}^{2}} \leq 0$ and $\frac{\mathrm{d} c}{\mathrm{~d} q_{1}}>0 ; \frac{\mathrm{d}^{2} p^{w}}{\mathrm{~d} q_{1}^{2}} \leq 0, \frac{\mathrm{d}^{2} c}{\mathrm{~d} q_{1}^{2}}$ implying a concave input demand and convex production costs and with $\mathrm{d} \lambda / \mathrm{d} q_{1} \geq 0$ implying that the shadow value must be weakly increasing in the input demand.

Observe that having $\lambda=0$ in Equation (11) implies a redundant balance constraint. But having the balance constraint bind with $\lambda>0$ implies that we must have:

$$
q_{1}^{*}=X-q_{2}
$$

where the optimal solution $q_{1}^{*}$ will be lower than the optimal output with a redundant balance constraint(or $\lambda=0$ ) because marginal profit remains positive. This corresponds to a situation in which although it is profitable to increase output, inadequate network capacity means that the producer must reduce output below what would otherwise be optimal. We can therefore identify the Cournot-optimal upstream output for producer $j=1$ to be a function of the rival's output, the average cost of production and the size of the total input demand:

$$
q_{1}^{*}=q_{1}^{*}\left(q_{2}, c, X\right)
$$

A symmetric function will be valid for the rival producer $j=2$.

\section{Comparative Statics}

Taking comparative statics on the first-order condition in (Equation (10)) shows that:

$$
\left.\frac{\mathrm{d} q_{j}^{*}}{\mathrm{~d} c}\right|_{\mathrm{d} L_{j}^{\prime}=0}=\frac{1}{\operatorname{SOC}\left(q_{j}\right)}<0
$$

which says that the optimal upstream output for producer $j=1 ; 2$ is decreasing in the average cost of upstream production at a rate equal to the inverse of the second-order condition.

From the binding supply-demand balance constraint in Equation (12) we can also ascertain that a marginal increase in the rival's upstream output $q_{2}$ while holding the total input demand $X$ constant, would require an equal decrease in $q_{1}$ meaning that:

$$
\left.\frac{\mathrm{d} q_{j}^{*}}{\mathrm{~d} q_{2}}\right|_{\mathrm{d} L_{j}^{\prime}=0}=-1<0
$$

Similarly, a marginal increase in $X$ while holding $q_{2}$ unchanged would require an equal increase in $q_{1}$ meaning that:

$$
\left.\frac{\mathrm{d} q_{j}^{*}}{\mathrm{~d} X}\right|_{\mathrm{dL} j_{j}^{\prime}=0}=1>0
$$




\section{The Incentive to Raise Network Costs}

We will in this section examine the incentives of a retail supplier (the predator) to strategically raise the network cost for itself and the retail rival. ${ }^{15}$ When there are negative externalities associated with the use of the infrastructure network, an expansion of the predator's input demand will suffice to raise networkcosts. ${ }^{16}$

For the predator, a rise in network costs will induce a fall in its input demand and will also affect its retail sales/quantity in the same way. However, since the rival's input demand and retail sales would also be negatively affected by the rise in the network cost, the predator will be able to expand its retail sales to compensate for the reduction in the rival's retail sales, meaning that the overall effect on the predator's retail sales may be ambiguous. A strategy of raising network costs would however be profitable for the predator when the resultant marginal revenue exceeds the marginal cost imposed by the strategy.

To examine these incentives closely, we may re-express the network cost as:

$$
M(X)=m(X)+y
$$

where $M(X)$ represents a family of cost curves defining the network cost as a function of total retail demand and a given level of the shift parameter $y \geq 0 .{ }^{17}$ Adopting the convention that $i=1$ is the predator and $i=2$ is the rival, retail supplier 1's payoff on the retail market may be written as:

$$
\tilde{\pi}_{1}^{r}=\left[p^{r}(X)-[m(X)+y]-p^{w}\right] x_{1}
$$

With the first-order condition:

$$
\widetilde{F O C}\left(x_{1}\right)=\frac{\mathrm{d} \tilde{\pi}_{1}^{r}}{\mathrm{~d} x_{1}}=\left[\frac{\mathrm{d} p^{r}}{\mathrm{~d} X}-\frac{\mathrm{d} m}{\mathrm{~d} X}\right] x_{1}+\left[p^{r}-m-y-p^{w}\right]=0
$$

which again says that marginal revenue is set to equal marginal cost on the retail market. The second-order condition is:

$$
\widetilde{\operatorname{SOC}}\left(x_{1}\right)=\frac{\mathrm{d}^{2} \tilde{\pi}_{1}^{r}}{\mathrm{~d} x_{1}^{2}}=\left[\frac{\mathrm{d}^{2} p^{r}}{\mathrm{~d} X^{2}}-\frac{\mathrm{d}^{2} m}{\mathrm{~d} X^{2}}\right] x_{1}+2\left[\frac{\mathrm{d} p^{r}}{\mathrm{~d} X}-\frac{\mathrm{d} m}{\mathrm{~d} X}\right]<0
$$

which is again satisfied by a concave retail demand and convex network costs. The impact of a small change in the network cost on the predator's retail profit can be seen by differentiating the profit function in Equation (21) with respect to the shift parameter $y$ :

$$
\frac{\mathrm{d} \tilde{\pi}_{1}^{r}}{\mathrm{~d} M}=\frac{\mathrm{d} \tilde{\pi}_{1}^{r}}{\mathrm{~d} y}=\left\{\left[\frac{\mathrm{d} p^{r}}{\mathrm{~d} X}-\frac{\mathrm{d} m}{\mathrm{~d} X}\right] x_{1}+\left[p^{r}-m-y-p^{w}\right] \frac{\mathrm{d} x_{1}}{\mathrm{~d} X}\right\} \frac{\mathrm{d} X}{\mathrm{~d} y}-x_{1}=0
$$

Differentiating the first-order condition in Equation (22) with respect to $y$ gives an expression for $d X / d y$ as:

$$
\frac{\mathrm{d} X}{\mathrm{~d} y}=\frac{1}{\widehat{\operatorname{SOC}}\left(x_{1}\right)}
$$

which says that a small rise in the network cost will reduce the total retail demand by a magnitude equal to the inverse of the second-order condition (expressed in absolute terms).

Differentiating the definition of the total retail quantity: $X=x_{1}+x_{2}$ with respect to $X$ gives an expression for $\mathrm{d} x_{1} / \mathrm{d} X$ as:

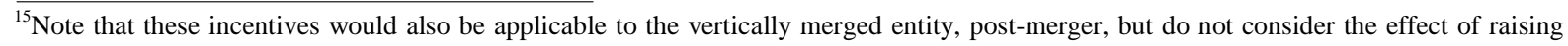
network costs on the merged producer's profit.

${ }^{16}$ The negative externality identified here arises because an expansion in the input demand of a single retail supplier results in a rise in the cost of using the network for all retail suppliers.

${ }^{17}[16]$ adopts a similar formulation in analysing the effect of raising the cost of an input factor of production on the industry rent. He denotes the factor cost as: $W(X)=w(X)+S$, where $X$ is the industry output and $S$ is a shift parameter. $W(X)$ is therefore a one-parameter family of curves, but is a given curve for a given value of $S$.
} 


$$
\frac{\mathrm{d} x_{1}}{\mathrm{~d} X}=1-\frac{\mathrm{d} x_{2}}{\mathrm{~d} X}
$$

Recognising Equation (25) and Equation (26) in Equation (24) and then recalling from the first-order condition in Equation (22) that:

$$
\left[p^{r}-m-y-p^{w}\right]=-\left[\frac{\mathrm{d} p^{r}}{\mathrm{~d} X}-\frac{\mathrm{d} m}{\mathrm{~d} X}\right] x_{1}
$$

gives:

$$
\frac{\mathrm{d} \tilde{\pi}_{1}^{r}}{\mathrm{~d} y}=-\frac{x_{1}\left\{\left[\frac{\mathrm{d}^{2} p^{r}}{\mathrm{~d} X^{2}}-\frac{\mathrm{d}^{2} m}{\mathrm{~d} X^{2}}\right] x_{1}+2\left[\frac{\mathrm{d} p^{r}}{\mathrm{~d} X}-\frac{\mathrm{d} m}{\mathrm{~d} X}\right]+\frac{\left[p^{r}-m-y-p^{w}\right]}{x_{1}} \frac{\mathrm{d} x_{2}}{\mathrm{~d} X}\right\}}{\widetilde{\operatorname{SOC}}\left(x_{1}\right)}
$$

The expression in Equation (27) shows that the impact of a small increase in the network cost on the predator's profit will be positive provided the numerator term within curly brackets is positive. Hence we must have:

$$
\left[\frac{\mathrm{d}^{2} p^{r}}{\mathrm{~d} X^{2}}-\frac{\mathrm{d}^{2} m}{\mathrm{~d} X^{2}}\right] x_{1}+2\left[\frac{\mathrm{d} p^{r}}{\mathrm{~d} X}-\frac{\mathrm{d} m}{\mathrm{~d} X}\right]+\frac{\left[p^{r}-m-y-p^{w}\right]}{x_{1}} \frac{\mathrm{d} x_{2}}{\mathrm{~d} X}>0
$$

The interpretation of Equation (28) is intuitive. It says that the predator will evaluate the beneficiality of raising the network cost by examining the full impact of the attendant rise in costs on its profit.

First is the direct impact through a reduction in its own retail quantity and second is the indirect impact because its retail quantity must increase to compensate for the reduction in the rival's quantity. Observe that the first two terms in Equation (28) constitute the second-order condition in Equation (23) and show the reduction in the predator's marginal profit from the reduction in its retail quantity when the network cost rises. Conversely, the third term shows the average profit margin that the predator gains on each extra unit it sells to compensate for the reduction in the rival's retail quantity when the network cost rises.

Defining $\varepsilon_{p}=-\frac{p^{r}}{p^{r^{\prime}} x_{i}}$ and $\varepsilon_{m}=\frac{m}{m^{\prime} x_{i}}$ as the elasticity of retail demand and the elasticity of network capacity demand respectively, we can re-express Equation (28) as:

$$
\left[p^{r}-m-y-p^{w}\right] \frac{\mathrm{d} x_{2}}{\mathrm{~d} X}>2\left[\frac{p^{r}}{\varepsilon_{p}}+\frac{m}{\varepsilon_{m}}\right]-\left[p^{r^{\prime \prime}}-m^{\prime \prime}\right] x_{1}^{2}
$$

which summarises the condition under which a retail supplier would have the incentive to strategically predate on a rival by raising network costs. Equation (29) says that the marginal profit earned by the predator on the retail sales made to compensate for the reduction in retail sales by the rival (the left-hand side) must exceed the marginal profit lost from three sources:

1). The reduction in retail revenue when retail consumers respond elastically to a rise in the retail price that is passed on from a rise in the network cost, 2). The direct increase in network costs due to an expansion in the total retail sales, and 3). The product of the curvature difference between the retail demand and network cost functions and the square of the predator's retail sales (the right-hand side).

\section{Vertical Merger and Foreclosure}

We will make the assumption that the vertical merger occurs between retail supplier $i=1$ and input producer $j=1$. Given the profitability of raising network costs as established in Equation (29), a vertical merger will have four key strategic effects, each of which re-inforces the ability of the merged entity, post-merger, to feasibly and substantially foreclose the independent retail rival.

First, it will result in the reduction of the input cost for the vertically merged retail supplier that is due to eliminating the double marginalization effect. The input cost is now set equal to the average production cost for the 
vertically merged producer, the result of which is an expansion of input demand by the merged retail supplier. Second, the expansion of input demand raises network costs for both retail suppliers as presented in the previous section. $^{18}$

Observe from the first and second strategic effects that a vertical merger introduces cost asymmetry between the hitherto symmetric retail suppliers. The sum of the merged retail supplier's post-merger costs, that is, the input cost plus the network cost, will consequently understate that of the independent retail rival.

Third, vertical merger could result in the merged producer withdrawing from the input market, in which case the input market becomes monopolized by the independent producer. This means that the input cost borne by the independent retail rival will rise even further and the cost asymmetry will increase. ${ }^{19}$

Fourth, increased retail costs (that is, input plus network costs) will have a negative effect on the retail demand of each retail supplier. For the vertically merged retail supplier, a rise in the post-merger network costs means a reduced retail demand. This should however be balanced against the effect of eliminating doublemarginalization and the increase in its retail demand in order to compensate for the reduction in the independent retail rival's demand.

Summarily, strategic partial vertical integration, that is, a backward merger by a retail supplier with foreclosure intent, could result in an expansion of the retail supplier's market share and an expansion of its retail margin, meaning that its profit increases.

\subsection{The Retail Market}

Post-merger, the vertically merged entity will have the following objective function:

$$
\pi_{1}^{V I}=\pi_{1}^{r}+\pi_{1}^{w}=\left[p^{r}(X)-M(X)-c\left(x_{1}\right)\right] x_{1}
$$

which sums up the individual payoffs for retail supplier $i=1$ and producer $j=1$. Observe that the upstream output is now written as $x_{1}$.

The first-order condition with respect to $x_{1}>0$ is:

$$
\frac{\mathrm{d} \pi_{1}^{V I}}{\mathrm{~d} x_{1}}=\left[\frac{\mathrm{d} p^{r}}{\mathrm{~d} x_{1}}-\frac{\mathrm{d} M}{\mathrm{~d} x_{1}}-\frac{\mathrm{d} c}{\mathrm{~d} x_{1}}\right] x_{1}+\left[p^{r}-M-c\right]=0
$$

which equates the marginal revenue from retail market sales with the marginal cost of supply at the input market and network levels.

The second-order condition is:

$$
\frac{\mathrm{d}^{2} \pi_{1}^{V I}}{\mathrm{~d} x_{1}^{2}}=\left[\frac{\mathrm{d}^{2} p^{r}}{\mathrm{~d} x_{1}^{2}}-\frac{\mathrm{d}^{2} M}{\mathrm{~d} x_{1}^{2}}-\frac{\mathrm{d}^{2} c}{\mathrm{~d} x_{1}^{2}}\right] x_{1}+2\left[\frac{\mathrm{d} p^{r}}{\mathrm{~d} x_{1}}-\frac{\mathrm{d} M}{\mathrm{~d} x_{1}}-\frac{\mathrm{d} c}{\mathrm{~d} x_{1}}\right] \leq 0
$$

which is satisfied by the demand concavity and cost convexity assumptions. From (Equation (31)) we can define the vertically merged retail supplier's optimal retail quantity as:

$$
x_{1}^{* V I}=x_{1}^{* V I}\left(x_{2}, c\right)
$$

which will be larger than the optimal retail quantity under vertical separation: $x_{1}^{*}\left(x_{2}, p^{w}\right)$ given that $c<p^{w}$ and using the comparative static result in Equation (7) that the optimal retail quantity is decreasing in the input cost.

\subsection{The Input Market}

While the price of the input utilised by the vertically merged retail supplier is reduced to cost, the effect on the price of input utilised by the independent retail rival is more difficult to determine. One possible outcome of partial vertical integration is that the independent producer becomes the sole provider of the input to the inde-

\footnotetext{
${ }^{18}$ For this to be true, that is, for retailer $i$ 's input demand to increase following a backward merger, it is natural to assume that the expansion in $i$ 's input demand due to eliminating double marginalization, exceeds the reduction in input demand due to the rise in network costs.

${ }^{19} \mathrm{An}$ alternative and highly plausible post-merger scenario is one in which the merged entity withdraws only partially from the input market that is, the integrated retail supplier is in principle still able to purchase externally on the input market.
} 
pendent retailer, with the implication that it can now exercise monopoly power by raising the input price above the Cournot-duopoly price.

To show how the input price on a monopolized input market is determined, assume that independent producer $j=2$ has the Lagrange formulation:

$$
L_{2}^{m}\left(q_{2}, \lambda^{m}\right)=\left[p^{w}\left(X-x_{1}^{* V I}\right)-c\left(q_{2}\right)\right] q_{2}+\lambda^{m}\left[X-x_{1}^{* V I}-q_{2}\right]
$$

where the residual or monopoly demand it faces on the input market is defined as the total input demand less the internalised input demand of the vertically merged retail supplier. $\lambda^{m}$ is the multiplier on the supply-demand balance constraint.

Solving the Lagrange problem with respect to $q_{2}>0$ gives the monopoly first-order conditions as:

$$
\frac{\mathrm{d} L_{2}^{m}}{\mathrm{~d} q_{2}}=\left[\frac{\mathrm{d} p^{w}}{\mathrm{~d} q_{2}}-\frac{\mathrm{d} c}{\mathrm{~d} q_{2}}\right] q_{2}+p^{w}-c-\lambda^{m}=0
$$

And

$$
\frac{\mathrm{d} L_{2}^{m}}{\mathrm{~d} \lambda^{m}}=X-x_{1}^{* V I}-q_{2}=0 ; \quad \lambda^{m} \geq 0
$$

which as before, show that marginal revenue must equal marginal cost and the supply-demand balance must be satisfied for the entire input market (including the merged entity's input demand). ${ }^{20}$

The second-order condition is:

$$
\frac{\mathrm{d}^{2} L_{2}^{m}}{\mathrm{~d} q_{2}^{2}}=\left[\frac{\mathrm{d}^{2} p^{w}}{\mathrm{~d} q_{2}^{2}}-\frac{\mathrm{d}^{2} c}{\mathrm{~d} q_{2}^{2}}\right] q_{2}+2\left[\frac{\mathrm{d} p^{w}}{\mathrm{~d} q_{2}}-\frac{\mathrm{d} c}{\mathrm{~d} q_{2}}\right] \leq 0
$$

which allows us to define the independent producer's optimal input market quantity as:

$$
q_{2}^{m^{*}}=q_{2}^{m^{*}}\left(X-x_{1}^{* V I}, c\right)
$$

The 'monopoly' input quantity sold by the independent producer is a function of the residual input demand(after excluding the input demand served by the vertically merged retail supplier) and the average production cost. Inasmuch as $x_{1}$ expands following the vertical merger, holding the total retail demand $X$ constant means that the residual retail demand $x_{2}$ reduces. The independent retail supplier therefore loses retail market share to the merged rival and suffers a contraction of its retail profit margin as the cost of the input rises.

If $X$ expands following the vertical merger, not only does the independent retail supplier loose retail market share, but the contraction in its retail profit margin is stronger as the expansion in the total retail demand means that network costs will also rise. ${ }^{21}$

\section{The Effect on Retail Prices with Linear Demand}

In order to precisely identify the effects of a vertical merger and foreclosure on retail prices in this environment, we will now examine the special case with linear retail demand.

Recall the definition of retail supplier i's payoff in Equation (2) as:

$$
\pi_{i}^{r}=\left[p^{r}(X)-M(X)-p^{w}\right] x_{i}
$$

and assume the linear retail inverse demand function:

$$
p^{r}(X)=A-b X
$$

\footnotetext{
${ }^{20} \mathrm{~A}$ way of thinking about this is that in the eventuality that the merged entity is unable to fully satisfy its input demand internally, then it will have recourse to the external input market.

${ }^{21}$ The outcome in which the total retail demand $\mathrm{X}$ becomes smaller following the vertical merger is not considered as it would imply that the expansion in the merged retail supplier's quantity be exceeded by the contraction in the independent retail supplier's demand. This is however not plausible as it would immediately reveal that anticompetitive foreclosure has occurred, there by making the strategy unsustainable.
} 
The inverse demand has the intercept: $A>0$ and says that the retail price is decreasing in the total retail demand $X$ at a rate equal to $b>0$. Assume that the network transport cost per-unit of input is represented by the simplified linear function:

$$
M(X)=\theta X
$$

with $M^{\prime}(X)=\theta>0$, which says that the network cost is positive and increasing in the total retail demand at a constant rate equal to $\theta$ which is parametrically specified. ${ }^{22}$

Recall also the definition of producer $j$ 's payoff in Equation (1) where $p^{w}(Q)$ is, as earlier, the input market's inverse demand function evaluated at the total input market output $Q$. The average production cost is: $c\left(q_{j}\right)$ with the total production cost denoted as: $C_{j}\left(q_{j}\right)=c\left(q_{j}\right) q_{j}$ and the marginal production cost denoted as:

$$
C_{j}^{\prime}\left(q_{j}\right)=c\left(q_{j}\right)+c^{\prime}\left(q_{j}\right) q_{j}>0
$$

\subsection{Vertical Separation with Linear Demand}

In this sub-section we will derive the pre-merger outcomes on the retail and input markets. As earlier, the backward induction approach is adopted.

\subsubsection{The Retail Market}

Retail supplier $i=1$ 's first-order condition with $x_{1}>0$ will be:

$$
\frac{\mathrm{d} \pi_{1}^{r}}{\mathrm{~d} x_{1}}=A-2 b x_{1}-b x_{2}-2 \theta x_{1}-\theta x_{2}-p^{w}=0
$$

which defines the Cournot reaction function as:

$$
x_{1}\left(x_{2}\right)=\frac{A-p^{w}(Q)}{2[b+\theta]}-\frac{x_{2}}{2}
$$

with retail supplier symmetry we can identify that:

$$
x_{1}^{*}=x_{2}^{*}=\frac{A-p^{w}(Q)}{3[b+\theta]}
$$

which says that a retail supplier's sales will in equilibrium be increasing in the intercept of the retail demand function, but will be decreasing in the input price $p^{w}(Q)$, in the slope of the inverse demand function $b$, and in the network cost parameter $\theta$.

\subsubsection{The Input Market}

Recognising from Equation (45) that the equilibrium total retail demand will be: $X^{*}=x_{1}^{*}+x_{2}^{*}$, we can define the input market's inverse demand function as:

$$
p^{w}(Q)=A-\frac{3}{2}[b+\theta] X
$$

Recall that the supply-demand balance constraint must always be satisfied, meaning that in the input market equilibrium we must have: $X=Q=q_{1}+q_{2}$. Using Equation (46) in the producer's payoff in Equation (1) gives the first-order condition for $q_{1}>0$ as:

$$
\frac{\mathrm{d} \pi_{1}^{w}}{\mathrm{~d} q_{1}}=A-3[b+\theta] q_{1}-\frac{3}{2}[b+\theta] q_{2}-C_{1}^{\prime}\left(q_{1}\right)=0
$$

\footnotetext{
${ }^{22}$ The network cost function is clearly an extreme specification of the network transport cost, but has the advantage of simplicity while showing the required property of increasing in the total retail demand.
} 
which gives producer $j=1$ 's Cournot reaction function to be

$$
q_{1}\left(q_{2}\right)=\frac{A-C_{1}^{\prime}\left(q_{1}\right)}{3[b+\theta]}-\frac{q_{2}}{2}
$$

with producer symmetry and $C_{1}^{\prime}=C_{2}^{\prime}$ we can now identify that:

$$
q_{1}^{*}=q_{2}^{*}=\frac{2\left[A-C_{1}^{\prime}\right]}{9[b+\theta]}
$$

which says that producer $j$ 's equilibrium input market quantity will be increasing in the intercept of the retail demand function, but will be decreasing in the marginal production cost $C_{1}^{\prime}$, in the slope of the retail inverse demand function $b$ and in the network cost parameter $\theta$.

Recognising Equation (49) in Equation (46) with $X=q_{1}^{*}+q_{2}^{*}$ gives:

$$
p^{w}(Q)=\frac{1}{3}\left[A+2 C_{1}^{\prime}\right]
$$

which intuitively says that the equilibrium input market price will be increasing in the intercept of the retail demand function and in the input's marginal production cost. Having $q_{1}^{*}>0$ in Equation (49) implies that we must also have:

$$
A>C_{1}^{\prime}
$$

Inserting Equation (50) into Equation (45) then gives each retail supplier's optimal quantity as:

$$
x_{1}^{*}=x_{2}^{*}=\frac{2\left[A-C_{1}^{\prime}\right]}{9[b+\theta]}
$$

and by recognizing in Equation (40) that $X=x_{1}^{*}+x_{2}^{*}$, we can identify the equilibrium retail market price to be:

$$
p_{v s}^{r}(X)=\frac{[5 b+9 \theta] A+4 b C^{\prime}}{9[b+\theta]}
$$

which infers that the retail price will be increasing in the network cost parameter $\theta$ provided that:

$$
\frac{\mathrm{d} p^{r}}{\mathrm{~d} \theta}=\frac{4 b A}{9[b+\theta]^{2}}>0
$$

which is always satisfied, and in the slope of the retail inverse demand function $b$ provided that:

$$
\frac{\mathrm{d} p^{r}}{\mathrm{~d} b}=\frac{4 \theta\left[C_{1}^{\prime}-A\right]}{9[b+\theta]^{2}}<0
$$

which will be satisfied provided Equation (51) is true.

\subsection{Vertical Merger and Foreclosure with Linear Demand}

In this sub-section, we will derive the effects of a vertical merger and foreclosure with a linear demand on retail prices. As mentioned in an earlier section, the effect on the retail price is highly dependent on the post-merger outcome on the input market and we will consider two possible scenarios:

Case 1: The vertically merged entity withdraws completely from the input market, allowing the monopolisation of this market by the independent producer.

Case 2: The vertically merged entity withdraws only partially from the input market, with the merged retail supplier (in principle) still able to purchase externally on the input market. This corresponds with the realistic post-merger scenario in which all upstream production capacity within the merged entity is dedicated for "internal" 
usage, while inadequate internal production is met by purchasing from an external input market. ${ }^{23}$

\subsubsection{The Retail Market}

Differentiating the vertically merged retail supplier's pay-off function with respect to its retail quantity $x_{1}>0$ gives the first-order condition:

$$
\frac{\mathrm{d} \pi_{1}^{r}}{\mathrm{~d} x_{1}}=A-2[b+\theta] x_{1}-[b+\theta] x_{2}-C_{1}^{\prime}=0
$$

where $C_{1}^{\prime}$ is the internal transfer price for the input within the merged entity. From the FOC we can define the Cournot reaction function as:

$$
x_{1}\left(x_{2}\right)=\frac{\left[A-C_{1}^{\prime}\right]}{2[b+\theta]}-\frac{x_{2}}{2}
$$

and for the independent retail rival we will have the Cournot reaction function:

$$
x_{2}\left(x_{1}\right)=\frac{\left[A-p_{2}^{w}\right]}{2[b+\theta]}-\frac{x_{1}}{2}
$$

where $p_{2}^{w}$ is the input price on the post-merger "external" input market. Due to the vertical merger and the resulting foreclosure effects, the input costs for the two retail suppliers will be asymmetric with:

$$
C_{1}^{\prime} \leq p_{2}^{w}
$$

Inserting Equation (58) into Equation (57) gives the optimal quantities as:

$$
x_{1}^{*}=\frac{A-\left[2 C_{1}^{\prime}-p_{2}^{w}\right]}{3[b+\theta]}
$$

and:

$$
x_{2}^{*}=\frac{A-\left[2 p_{2}^{w}-C_{1}^{\prime}\right]}{3[b+\theta]}
$$

which says that a retail supplier's optimal quantity is increasing in the intercept of the retail demand function, but will be decreasing in the difference between twice its input cost and the input cost for the rival retail supplier. Finally, it is decreasing in the sum of the slope of the inverse demand function $b$ and the network cost parameter $\theta$.

Observe that the difference between the quantities for both retail suppliers can be expressed as:

$$
\Delta x^{*}=x_{1}^{*}-x_{2}^{*}=\frac{p_{2}^{w}-C_{1}^{\prime}}{b+\theta}>0
$$

which is positive when the input cost for the independent retail supplier exceeds the marginal production cost of the merged entity. An inference from Equation (62) is that by asymmetrically raising the input costs for both retail suppliers, a vertical merger allows the lower cost retail supplier to "steal" market share from the rival.

\subsubsection{The Input Market-Case 1}

If the vertically merged producer and retail supplier withdraw completely from the input market, then the input market will be monopolised by the independent producer $j=2$. This means that the input market demand can

\footnotetext{
${ }^{23}$ Case 2 is a more realistic post-merger scenario than case 1 , which is more familiar from the vertical foreclosure literature such as [5]. Take for example the electricity industry where a vertical merger may be motivated by the need to physically hedge against non-delivery risk, resulting in a retail supplier buying up a number of power plants. Since this action is intended to hedge risk, it is unlikely that it will fully cover the retail supplier's retail obligations, thereby opening the possibility for occasional purchases from the external input market. Also, although we have specified otherwise here, it is unlikely that the merged entity will always have a lower marginal cost than the input market. It may therefore purchase externally when the input market price is lower than the internal transfer price..
} 
be derived from Equation (61) as:

$$
p_{2}^{w}=\frac{A+C_{1}^{\prime}-3[b+\theta] q_{2}}{2}
$$

with $x_{2}=q_{2}$. The independent input producer's payoff will then be:

$$
\pi_{2}^{w}=\frac{1}{2}\left[A+C_{1}^{\prime}\right] q_{2}-\frac{3}{2}[b+\theta] q_{2}^{2}-C_{2}\left(q_{2}\right)
$$

from which we obtain the first-order condition with respect to $q_{2}>0$ as:

$$
\frac{\mathrm{d} \pi_{2}^{w}}{\mathrm{~d} q_{2}}=\frac{1}{2}\left[A+C_{1}^{\prime}\right]-3[b+\theta] q_{2}-C_{2}^{\prime}=0
$$

which gives the optimal (monopolized) input market quantity as:

$$
q_{2}^{* m}=\frac{A+C_{1}^{\prime}-2 C_{2}^{\prime}}{6[b+\theta]}=x_{2}^{*}
$$

which is also the retail market quantity for the independent retail supplier $i=2$. The input price in Equation (63) can now be identified as:

$$
p_{2}^{* w}=\frac{A+C_{1}^{\prime}+2 C_{2}^{\prime}}{4}
$$

Then inserting Equation (67) in Equation (60) identifies the vertically integrated retail supplier's optimal quantity to be:

$$
x_{1}^{*}=\frac{5 A-7 C_{1}^{\prime}+2 C_{2}^{\prime}}{12[b+\theta]}
$$

and by summing-up Equation (68) and Equation (66) with:

$$
C_{1}^{\prime}=C_{2}^{\prime}=C^{\prime}
$$

we obtain the total retail market quantity as:

$$
X=x_{1}^{*}+x_{2}^{* m}=\frac{7\left[A-C^{\prime}\right]}{12[b+\theta]}
$$

and the retail price as:

$$
p_{v f 1}^{r}(X)=\frac{[5 b+12 \theta] A+7 b C^{\prime}}{12[b+\theta]}
$$

\subsubsection{The Input Market-Case 2}

If the vertically merged entity withdraws only partially from the input market, this means that the independent producer $j=2$ will, in principle, be able to supply input to both retail suppliers. Summing up Equation (60) and Equation (61) gives the total retail demand as facing $j=2$ as:

$$
X=x_{1}+x_{2}=\frac{2 A-C_{1}^{\prime}-p_{2}^{w}}{3[b+\theta]}
$$

where $C_{1}^{\prime}\left(q_{1}\right)$ is the internal transfer price for the merged entity. This allows us to define the inverse demand function on the input market as:

$$
p_{2}^{w}=2 A-3[b+\theta] X-C_{1}^{\prime}
$$


Then recognising Equation (73) in the payoff for the independent producer with: $X=Q=q_{1}+q_{2}$ gives this as:

$$
\pi_{2}^{w}=\left[2 A-3[b+\theta] Q-C_{1}^{\prime}\right] q_{2}-C_{2}\left(q_{2}\right)
$$

with the first order condition with respect to $q_{2}>0$ given as:

$$
\frac{\mathrm{d} \pi_{2}^{w}}{\mathrm{~d} q_{2}}=2 A-C_{1}^{\prime}-C_{2}^{\prime}-6[b+\theta] q_{2}-3[b+\theta] q_{1}=0
$$

from which we can derive the independent producer's reaction function as:

$$
q_{2}^{*_{m}}=\frac{A-C^{\prime}}{3[b+\theta]}-\frac{q_{1}}{2}
$$

given that Equation (69) is true. Recalling the merged entity's reaction function from Equation (57) as:

$$
q_{1}\left(q_{2}\right)=\frac{A-C^{\prime}}{2[b+\theta]}-\frac{q_{2}}{2}
$$

and inserting this in Equation (76) gives:

$$
q_{2}^{*}=\frac{A-C^{\prime}}{9[b+\theta]}
$$

using which in Equation (77) also gives:

$$
q_{1}^{*}=\frac{4\left[A-C^{\prime}\right]}{9[b+\theta]}
$$

which means that the total input demand will be:

$$
X=q_{1}^{*}+q_{2}^{*}=\frac{5\left[A-C^{\prime}\right]}{9[b+\theta]}
$$

and that the equilibrium retail price will also be:

$$
p_{v f 2}^{r}(X)=\frac{[4 b+9 \theta] A+5 b C^{\prime}}{9[b+\theta]}
$$

\section{Discussion}

The propensity of a cost-raising vertical merger to result in anticompetitive foreclosure lies in its ability to impact retail costs (that is, the sum of the input and network costs) for the merged entity and the independent retail rival asymmetrically. A vertical merger means that the sum of the input and network costs for the merged retail supplier fall below the corresponding costs for the independent retail rival. This is because for the vertically merged retail supplier, the input cost falls to the marginal production cost due to the elimination of double marginalization, while the network cost rises due to the presence of network externalities in the network infrastructure.

For the rival retail supplier, when the vertical merger results in the merged producer withdrawing from the input market, monopolisation can plausibly result—which will raise the input cost. The network cost also rises due to network externalities. Consequently, the independent retail rival faces foreclosure.

Paragraph 32 in the guidelines is intended to provide a clear basis for assessing, prior to a merger, when a vertical merger would, post-merger, stand a high chance of being anticompetitive. The three grounds for forming such an opinion are the ability and incentive of the merged-entity to practice foreclosure, and the impact that this will have on retail prices. In a network industry we have examined, the potential for vertical mergers with anticompetitive foreclosure to emerge is increased because the negative externality property of an infrastructure 
network, creates an ideal environment for raising rivals' costs. Besides, access to the network is an essential input to retail suppliers in the downstream network industry, meaning that raising the network costs for a retail rival would tend to be readily noticeable in its retail price. This means that the "ability to foreclose" following a network industry vertical merger can be significantly strong. The tendency of deregulated entities in network industries to use the network infrastructure strategically is not new. For example, [19] examines the strategic congestion of an electricity network by rival oligopolists in order to beneficially influence competitive outcomes. Also, [13] reviews the monopolization of the United States' petroleum refining sector by Standard Oil in the late nineteenth century, with the hypothesis that this was only feasible through Standard Oil's enforcement of a transportation cartel governing refining shipments through the railroad network.

Assessing the "incentive to foreclose" through the network can be somewhat more challenging, since raising the network cost would, at least on the face of it, also be costly to the merged entity and therefore unprofitable. A key insight is however to be found in paragraph 42 of the guidelines:

The incentive for the integrated firm to raise rivals' costs further depends on the extent to which downstream demand is likely to be diverted away from foreclosed rivals and the share of that diverted demand that the downstream division of the integrated firm can capture.

The condition in Equation (29) establishes that raising the network cost can be profitable inasmuch as it induces a contraction in the rival's retail demand, which can then be replaced by an expansion in the merged entity's retail market share. The profitability of this strategy however rests on the positive profit margin gained from the expansion (that is, on the left-hand side) exceeding the loss due to a profit margin contraction from a possible reduction in price, in order to sell more, and the attendant increase in the network cost (on the right-hand side). The key intuition here is therefore the profitable acquisition of market share by the predator, based on the cost asymmetry that foreclosure induces between the hitherto symmetric retail suppliers. Recall also the difference observed in the linear case in Equation (62) and the inference that foreclosure allows the predator to "steal" market share from the rival. Seen from a societal viewpoint, this need not be detrimental to consumers in the short-run, but a sustained alteration in market concentration over the longer-term, may create significant market power and a future platform for reducing consumer welfare.

Indeed, comparing the short-term impact on the retail price with linear demand shows that vertical merger and foreclosure does induce a fall in the retail price, relative to the vertical separation benchmark. The price is lowered when the merger results in the complete withdrawal of the merged entity from the input market, that is case 1, as shown by taking the difference between Equation (53) and Equation (71):

$$
p_{v s}^{r}-p_{v f 1}^{r}=\frac{5 b\left[A-C^{\prime}\right]}{36[b+\theta]}
$$

which is strictly positive. Similarly taking the difference between the retail price under vertical separation and the post merger outcome when the merged entity withdraws only partially from the input market, that is, case 2, in Equation (81) gives:

$$
p_{v s}^{r}-p_{v f 2}^{r}=\frac{b\left[A-C^{\prime}\right]}{9[b+\theta]}
$$

which is again strictly positive. ${ }^{24}$ These results should however be interpreted cautiously, given that (as argued in the preceding paragraph) a short-term fall in price that follows from a foreclosure strategy would only camouflage the potentially detrimental effects to competition and consumer welfare over the longer-term, as the predator succeeds in increasing its retail market share and thereby market power.

\section{Conclusion}

This paper has set out to examine the implications of paragraph 32 of the EU non-horizontal merger guidelines

${ }^{24} \mathrm{~A}$ comparison of the price in case 1 with 2 gives:

$$
p_{v / 2}^{r}-p_{v f 1}^{r}=\frac{b\left[A-C^{\prime}\right]}{12[b+\theta]}>0
$$

which suggests that a vertical merger followed by complete withdrawal of the merged entity from the input market may be better for consumers. 
for assessing the anticompetitive effects of vertical mergers with foreclosure within a network industry. The analytical model, quite understandably, represents a severe simplification of the real-world, but it justifiably gives useful insight into what a network industry supply chain would look like, post-merger, and into whether the controversy over the anticompetitive effects of vertical mergers may be resolved in favour of either the Chicago school, or the post-Chicago school.

\section{References}

[1] Bork, R.H. (1969) Vertical Integration and Competitive Processes. In: Weston, J.F. and Peltzman, S., Eds., Public Policy toward Mergers, Pacific Palisades, Los Angeles, 139-149.

[2] Bork, R.H. (1978) The Antitrust Paradox. New York.

[3] Posner, R.A. (1976) Antitrust Law. University of Chicago Press, Chicago.

[4] Posner, R.A. and Easterbrook, F.H. (1981) Antitrust. West Publishing, St. Paul.

[5] Ordover, J.A., Saloner, G. and Salop, S.C. (1990) Equilibrium Vertical Foreclosure. The American Economic Review, 80, 127-142.

[6] Salinger, M.A. (1988) Vertical Mergers and Market Foreclosure. The Quarterly Journal of Economics, 103, $345-356$. http://dx.doi.org/10.2307/1885117

[7] Rey, P. and Tirole, J. (2006) A Primer on Foreclosure. Forthcoming in: Armstrong, M. and Porter, R., Eds., Handbook of Industrial Organization III. http://idei.fr/doc/by/tirole/primer.pdf

[8] European Union. 2008/C 265/07. Guidelines on the Assessment of Non-Horizontal Mergers under the Council Regulation on the Control of Concentrations between Undertakings.

[9] Baker, J.B. (2001) A Preface to Post-Chicago Antitrust. http://ssrn.com/abstract=296119 http://dx.doi.org/10.2139/ssrn.296119

[10] Perry, M.K. (1989) Vertical Integration: Determinants and Effects. In: Schmalensee, R. and Willig, R.D., Eds., Handbook of Industrial Organization I, Elseveier Science, B.V., Amsterdam.

[11] Riordan, M. (2008) Competitive Effects of Vertical Integration. Forthcoming in: Buccirossi, P., Ed., Handbook of Antitrust Economics, MIT Press, Cambridge, 145-182.

[12] Salop, S.C. (2005) Anticompetitive Overbuying by Power Buyers. Antitrust L.J., 669-715. http://scholarship.law.georgetown.edu/facpub/211

[13] Granitz, E. and Klein, B. (1996) Monopolization by “Raising Rivals’ Costs”: The Standard Oil Case. Journal of Law and Economics, 39, 1-47.

[14] Krattenmaker, T.G. and Salop, S.C. (1987) Exclusion and Antitrust. Regulation. Nos. 3/4.

[15] Loertscher, S. and Reisinger, M. (2009) Competitive Effects of Vertical Integration with Downstream Oligopsony and Oligopoly. Governance and the Efficiency of Economic Systems (GESY). Discussion Paper No. 278.

[16] Nelson, R. (1957) Increased Rents from Increased Costs: A Paradox of Value Theory. Journal of Political Economy, 65, 387-393. http://dx.doi.org/10.1086/257957

[17] Scheffman, D.T. and Higgins, R.S. (2003) Twenty Years of Raising Rivals' Costs: History, Assessment, and Future. George Mason Law Review, 12, 371-388.

[18] Salop, S.C. and Scheffman, D.T. (1983) Raising Rivals’ Costs. The American Economic Review, 73, $267-271$.

[19] Borenstein, S., Bushnell, J. and Stoft, S. (2000) The Competitive Effects of Transmission Capacity in a Deregulated Electricity Industry. Rand Journal of Economics, 31, 294-325.

[20] Brueckner, J.K. and Spiller, P.T. (1991) Competition and Mergers in Airline Networks. International Journal of Industrial Organization, 9, 323-342. http://dx.doi.org/10.1016/0167-7187(91)90015-D

[21] Ivaldi, M. and McCullough, G.J. (2001) Density and Integration Effects on Class I U.S. Freight Railroads. Joumal of Regulatory Economics, 19, 161-182. http://dx.doi.org/10.1023/A:1011149324027

[22] Friebel, G., Ivaldi, M. and Pouyet, J. (2011) Competition and Industry Structure for International Rail Transportation. Idei Working Paper. http://idei.fr/doc/wp/2011/ivaldi_friebel_pouyet_2011.pdf

[23] Nerlove, M. (1963) Chapter 7. Returns to Scale in Electricity Supply. In: Christ, C., et al., Eds., Measurement in Economics, Stanford University Press, Palo Alto, 167-198.

[24] Kreps, D. and Scheinkman, J. (1983) Quantity Precommitment and Bertrand Competition Yield Cournot Outcomes. Bell Journal of Economics, 14, 326-337. http://dx.doi.org/10.2307/3003636

[25] Tirole, J. (1988) The Theory of Industrial Organization. MIT Press, Cambridge. 